\title{
Factors discouraging participation of girls in ICT education
}

\section{Scott Morton}

School of Information Technology

Whitireia Community Polytechnic

Wellington, New Zealand

Email: scott.morton@whitireia.ac.nz

\section{Petrea Redmond}

School of Teacher Education and Early Childhood

University of Southern Queensland

Toowoomba, Queensland

Email: Petrea.Redmond@usq.edu.au

\section{Peter Albion}

School of Teacher Education and Early Childhood

University of Southern Queensland

Toowoomba, Queensland

Email: Peter.Albion@usq.edu.au

\begin{abstract}
Despite expanding ICT job opportunities, there has been a decrease in the proportion of girls entering into ICT study, and pursuing ICT careers. This paper explores factors that discourage participation of high school girls in ICT using a modified version of the conceptual framework based on the "STEMcell" model. The modified framework was used to create an online questionnaire which gathered data from girls and boys between the ages of 15 and 17 years studying at high school. Each section of the framework used selected questions based on perceptions and attitudes to gain an insight into whether girls would be more likely to participate in ICT. The findings indicated that boys, more than girls sought advice from their family members on their future career choices. The results also showed stereotypes are still alive in girls more than boys and that girls are unlikely to follow a career in ICT. Moreover, girls more than boys disagree about ICT becoming compulsory in high school. Current number of enrolments of girls in ICT at high school lags behind that of boys and, until changes are made, girls going into the ICT industry will be in the minority.
\end{abstract}

Keywords Females, ICT, high school, stereotyping, role models, technology 


\section{Introduction}

This paper explores a problem that New Zealand and western culture has faced over many decades: female students have negative perceptions of ICT and do not perceive it to be a viable career choice. Researchers have concluded there is a problem, but have not found an answer to why the proportion of females enrolling in ICT at high school is low (Baruch 2014; Craig 2014). This research investigates the attitudes and perceptions of high school girls and how that influences them regarding ICT and related career choices. This study identifies effects, including perceptions, gender differences, influences and role models that discourage females from following a career path into ICT.

Western countries are seeing a shortfall of graduates coming out of university to fill the ever-increasing ICT job market (Birrell 2015; Cappelli 2015). In an investigation carried out by the Auckland Chamber of Commerce (ACC), 61,000 students were surveyed across Auckland high schools regarding ICT qualifications. Ryan (2015) interviewed Michael Barnett from the ACC, who raised a concern that only $6 \%$ of students in Auckland would gain the ICT skills necessary to get a job in the ICT industry immediately after high school. This reinforces a lack of ICT education within schools, and that the majority of school leavers do not have the basic ICT knowledge required by industry to get full time employment. As of May 2018, across Australia and New Zealand, there were approximately 18,00o job vacancies in the ICT industry compared to 12,500 jobs in the healthcare sector ("Seek ICT Jobs" 2018), which illustrates the availability of opportunities in ICT.

\section{Conceptual framework}

This study used a modified version of the conceptual framework designed by Bernhardt (2014) based on the "STEMcell” model (p. 18), where 'STEM' combines Information Technology (IT) in the broader STEM fields (Science, Technology, Engineering and Mathematics) and the 'Cell' looks at the individual (Bernhardt 2014). This framework is used as a lens to make a judgement about the likelihood of a student choosing ICT for study and future career, considering the constructs of Culture, \#SocialIT, Structure, Social factors. Each construct will contribute to decisions about choosing ICT as a career path. The adapted conceptual framework is shown in Figure 1.

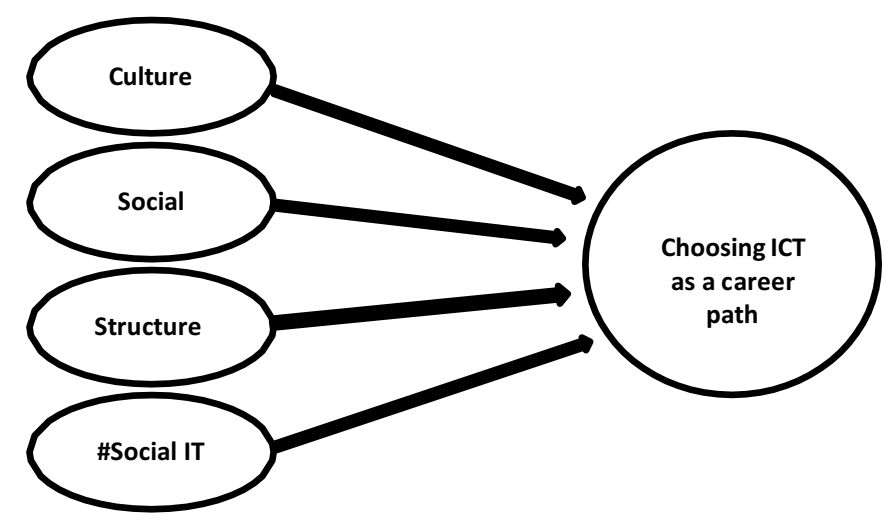

Figure 1. New Framework based on STEMcell model (Bernhardt 2014)

The adapted framework identifies four constructs: Cultural, \#SocialIT, Structural and Social, each with its own context and factors which may encourage or discourage participation, or present obstacles that incentives or disincentives participation in ICT. Each of the constructs from the framework is expanded through discussion of the literature to give background into some of the perceptions and attitudes that are to be measured through a questionnaire. The outputs of the four constructs are synthesized to form "the Likelihood of students choosing ICT".

\section{Literature review}

\subsection{Culture}

The cultural construct discusses popular culture and parental expectations that influence students when it comes to choosing ICT as a career. Popular culture is defined by Bernhardt (2014) as "the entirety of 
ideas, perspectives, attitudes, images and other phenomena that are within the mainstream of a given culture"(p. 102). These popular cultures can affect the way people view and interact with ICT.

Baby Boomers, Generation X and Y growing up had different popular cultures associated with each generation. Baby Boomers would have been the first generation that had access to television and easy access to music; both would have had an impact on their influences and choices (Wiedmer 2015). The end of Generation X and beginning of Generation $Y$ would have been the first generations to be fully exposed to computing. By the turn of the 80's, Generation X was exposed to more information than the Baby Boomers through media, TV and films, and popular culture, this then expanded into the computer field with the likes of computer games (Wiedmer 2015). Generation Y was the first generation to embrace the internet, and through that medium, a new popular culture arose; the online community. TV shows in the 90's brought new popular cultures to teenagers with the likes of 'The Simpsons' and 'reality TV'. Computers started to appear in households across western societies and popular TV shows started to appear as video games (Koulopoulos and Keldsen 2014).

Generation $\mathrm{Z}$ is the most connected generation when it comes to technology (Koulopoulos and Keldsen 2014). The effects of popular culture among Generation $Z$ students could possibly change their perceptions through popular TV shows such as 'Appsolute Genius on CBBC' and computer games such as 'Minecraft'. These popular cultures are exposing children at an early age to technology and future jobs (Bernhardt 2014).

Parental expectations are influenced by their cultural norms, "the less rigid and less influential the freer and more cosmopolitan the society is" (Bernhardt 2014, p. 103). The generational influence of family members on children can become the catalyst for the direction they take while at high school. Dimitriadi (2013) observed that family is the main avenue for children to discuss ideas for career choices. Family can be very influential and the desire to follow in the footsteps of one's parents has long been a significant factor in the choice of career. If children view their parents as role models they will be strongly influenced in their choices of career (Outlay et al. 2017).

As Generation Y become parents themselves the generational effect will affect how their children use and understand technology. Bernhardt (2014) stated, "Tomorrow's parents are today's highly econnected teenagers" (p. 104).

\section{2 \#Social IT}

The \#Social IT construct incorporates the factors of the ever-changing landscapes of social media, the terminology used, and the technology that Generation Z are using. \#SocialIT represents \#SocialEra, the current disruptive technology, in its application as an influencing platform/environment for students in ICT. The \#SocialEra or Social Disruptive Era is the name given to the new age of social technologies that are being used in the $21^{\text {st }}$ century. Social technologies include Facebook, Instagram, WhatsApp, Tumblr, Google+, YouTube, Pinterest, Snapchat and many more. \#SocialIT represents the transformation of technology and how it will shape the future of IT (Bernhardt 2014). It considers some of the influential factors that young people will be faced with in the coming years such as social, educational and career implications in a fast-moving landscape of the IT industry. Today's Generation $\mathrm{Z}$ students have adopted these disruptive and enabling technologies at such a rapid rate that technology has become an integral part of their lives.

The power of social media has an opportunity to offer Generation $\mathrm{Z}$ girls a different outlet to express their creativity within a 'net neutral' world (Bernhardt 2014). With the likes of Facebook, Twitter, Instagram, Snapchat and many more being used in this revolution, young girls can prosper and show the world that girls too belong in the new disruptive landscape (Bernhardt 2014).

\subsection{Structure}

The structural construct discusses the factors that influence Generation Z through work and high school, such as teachers, career advisors and the ICT industry. The structural influencing factors that interact with the construct include education, information, access, support mechanisms and government policies.

Most career paths are chosen early in the student's educational life (Broadley 2015) and the lack of understanding of what is available in the ICT industry could be a factor in putting students, especially girls off ICT opportunities (Dimitriadi 2013). As suggested by Dimitriadi (2013) a reform of the curriculum has to take place to engage students but especially girls in ICT subjects. Bernhardt (2014) talked about a change in curriculum and a more agile approach to the problem, stating "we cannot properly teach modern ICT without embracing it ourselves" (p. 142). The high school education sector 
does have issues in recruiting new teaching staff into ICT subjects (Jones et al. 2016). However, teachers that take up the challenge are normally Generation Y, as they are more enthusiastic about technology (Dimitriadi 2013).

A study carried out in Australia by Clayton (2006) showed female students are choosing healthcare and medical careers instead of ICT careers, even though those jobs on average are lower paid than those in the ICT industry ("Seek ICT Jobs" 2018). In 2010, according to an analysis of Labour Department data in the US, women held 23.9\% of high tech jobs, down from 25.1\% in 2005 (Fortt 2013). The Australian Computer Society (ACS) in 2012 showed a decline to 19.73\% ("2012 Australian ICT Statistical Compendium" 2012) for women in the ICT industry. New Zealand census statistics showed in 2006, women represented $29 \%$ of employees in the ICT industry but the 2013 census showed a drop to $27 \%$ ("2013/2017 New Zealand Census" 2017). Craig (2014) research found that the percentage of girls entering degree courses for ICT related programmes is decreasing and the number of girls being employed in the ICT industry is representative of the shrinking number coming through from universities. There has been a decline in the number of women entering the ICT industry in the last two decades due to reluctance to take ICT subjects at a higher level (Broadley 2015).

Influencing factors for career choice by girls can start at school. The learning experiences through teachers and the curriculum can have an important effect on both the student's self-efficacy and their outcome expectations (Broadley 2015). Adya and Kaiser (2005) noted a gender bias and stated, "career advisors tend to reflect a gender bias when directing girls towards traditional careers and males to nontraditional careers" (p. 10). Adya and Kaiser (2005) suggested this was because career advisors felt more comfortable when advising in more traditional fields as they lack understanding and sufficient background in ICT to be aware of potential career paths. Further, they found that career advisors are out of touch with what is happening within the world of ICT. This problem is having a social impact on the ICT industry and Generation Z student's career paths. Career advisors are ill prepared for this disruptive technology and cannot keep up to date with the industry (Piyasiri et al. 2014).

\subsection{Social}

The social construct incorporates the factors that influence Generation $\mathrm{Z}$ through social interaction via media, peers, role models and mentoring. Clayton (2006) noted: "Australian girls are continuing to reject ICT careers partially due to negative perceptions and stereotypes” (p. 3388). This 'geeky' or 'nerdy' stereotype, which has been around for many decades, has a negative connotation putting many girls off studying ICT subjects at high school and beyond (Bernhardt 2014). Generation Z is obsessed with technology and devices and using such devices to interact with social media or to play games. This 'obsession' is replacing these older stereotypical views, but this new label of 'obsession' could be more difficult to counter than the 'geek' and 'nerdy' image it is replacing (Almond 2013).

Film, television, print and electronic media can influence and also enhance the stereotype that ICT is a male occupation (Bernhardt 2014; Clayton et al. 2012). This stereotype mainly focuses on visual images such as the 'geek' in the glasses and the darkened room of a teenage male in front of a computer screen, rather than representing ICT as a career choice and a viable option for girls (Gorden 2011). Young adults' perceptions about ICT jobs are biased by media influences and how these depict people in the industry, rather than being influenced by facts and figures about the actual people in the industry (Pau 2009). Girls' perceptions of ICT jobs mirror the stereotypes they have been presented throughout their teen years through television, film and other popular media. Television programs such as 'Criminal Minds' give the perception of ICT as being 'geeky', stating "the tech with the glasses" (Clayton et al. 2009, p. 156) and when shown in the program the female character is always portrayed working alone in a small dark room. However, Generation $\mathrm{Z}$ is using more of a dynamic platform through social media; their stereotypical views may differ from those perceived by other generations that use traditional media such as newspapers and TV (Jones and Ramanau 2009).

"The 'nerdy' image of the ICT industry is still seen as a major concern for most girls" (Bernhardt 2014, p. 105). Attitudes are evolving with every change in generation with regards to stereotypes. The problem becomes a generational problem, as the older generations such as the Baby Boomers, keep the stereotypical image alive. Bernhardt (2014) talked about today's younger generation in respect to attitudes and beliefs and stated "if today's youths were surveyed in the absence of preconceptions from the industry's history the results would already be markedly different" (p. 107).

Student career choices can be influenced in many ways; role models are one of these influencers (Adya and Kaiser 2005). Perciva (2014) found attractive looking female role models in STEM subjects not only decreased girls' interest in STEM subjects but also decreased their beliefs in their own ability to succeed at those subjects and the likelihood of studying them. Seeing attractive women as role models can 
become demotivating to young girls as their own self-image does not match up. Media attention in the past few years has focused on prominent males in ICT roles such as the late Steve Jobs, Bill Gates or Mark Zuckerberg. These role models reinforce the way girls and especially young girls view the ICT industry as being white middle class male-dominated (Gorden 2011). However, as the Baby Boomer generation move out of the ICT workforce and are replaced with Generation X or, more than likely, Generation Y workers, there could be a shift in appointments towards a more balanced workforce, and towards female workers (Wiedmer 2015). The following section outlines the method used to gather data from the students and describe how the results were analysed.

\section{Method}

Data were collected through an online questionnaire. The analysis is based on year 11 students studying at high schools within the Wellington region. Eight high schools responded to the initial research proposal; of those eight high schools, six allowed the research to take place. After ethical approval had been granted the questionnaire was distributed online using LimeSurvey.

\subsection{Questionnaire description}

The questionnaire was presented in five sections. Four sections, B through E are based on Bernhardt's adapted STEMCell framework. Questions A1 through A4 ask basic demographics of the student, B1 through B9 determined the background and family values based on perceptions of family input into the participant's future career path and knowledge about ICT and the industry. Questions C1 through C9 were devoted to social impact and the influence and perceptions that participants have through stereotypes, friends and role models. Questions D1 through D10 are all based on the structural factors that influence the participant through home, high school and industry. Questions E1 through E7 are questions looking at perceptions participants have of the future of ICT and what it will look like when they leave high school.

The questionnaire uses a Likert scale from one to five, one being 'completely disagree' and five being 'completely agree'. The questions were piloted through a high school that did not take part in the data collection phase. The questions were then modified based on the results of the validation test and some questions were dropped from the final questionnaire. Each construct has certain factors based on the type of information required to check perceptions and attitudes. As shown above in the literature for each of these constructs different areas have been examined to elicit types of questions required to gather data about those perceptions and attitudes.

\subsection{Analysis techniques}

For all analysis within this research, SPSS V.23 (Statistical Package for the Social Sciences) was used to calculate the results from the data gathered. The first technique used was to conduct frequency analysis, which shows the number of students answering the questions. Validation and reliability tests were carried out, comparing the constructs against each of the questions. This found errors of categorisation for some of the questions, which were then transferred into the correct constructs.

The second procedure carried out on the data was a normality test. It is an assumption of parametric statistics that continuous variables achieve normality. This test checks the skewness and kurtosis of the data, and gives values for each and their standard error. However, from the analysis carried out on the question sets, the data is either skewed + or - or has kurtosis and cannot be manipulated by a mathematical formula to bring back into a normal distribution. This being the case, non-parametric testing was carried out instead.

The third procedure carried out on the data was a reliability and validity test using Cronbach's Alpha. This procedure was used to determine the internal consistency and reliability of scaled data for each section of the questionnaire. Based on the reliability test, questions were deleted from sections of the questionnaire, which gave an 0.8 Cronbach alpha result, demonstrating that the final usable data was reliable and valid.

The fourth procedure carried out on the data was a Chi-Squared (CS) test. This statistic is used to test the Ns on the level of a single variable to see if they significantly differ from what is expected. The test is undertaken when data cannot be normalized by using a normality test. This test was to determine if there are significant differences in the level of a single variable in relation to the frequencies of those levels. Gender was used as the single variable and the file split into Female and Male using SPSS. 


\section{Results}

\subsection{Section A - Demographics}

The questionnaire was available for just over one month. In that month, 358 responses were received to the LimeSurvey application server, however, out of the 358 responses, 72 students' results had to be been removed, due to not enough questions being completed. From the 286 completed questionnaires, 167 were from girls and 119 from boys. This is illustrated in Table 1, which presents the gender details of the participants. There is slightly a bigger - percentage of girls than boys in the study. This is within the tolerance (+/- 5\%) of New Zealand statistics for high school students ("2013/2017 New Zealand Census" 2017).

\begin{tabular}{lll}
\hline Gender & Frequency & Per cent \\
\hline Female & 167 & 58.4 \\
Male & 119 & 41.6 \\
Total & 286 & 100 \\
\hline
\end{tabular}

\section{Table 1. Gender}

Table 2 shows the breakdown of questionnaire participants from an ethnicity perspective. The majority of the students that took part in the questionnaire classified their ethnicity as European (37.1\% overall), followed by New Zealander (32.9\% overall). The smallest group came from the Middle East, Latin America and Africa (2.4\% overall).

\begin{tabular}{lllllll}
\hline Gender & European & $\begin{array}{l}\text { New } \\
\text { Zealand }\end{array}$ & Maori & Pacific & Asian & Others \\
\hline Female & 60 & 61 & 10 & 17 & 6 & 13 \\
Male & 46 & 33 & 5 & 16 & 9 & 10 \\
Total & 106 & 94 & 15 & 33 & 15 & 23 \\
\hline
\end{tabular}

Table 2. Ethnicity

The final question within the demographic section looked at what industry participants presently wanted to go into when they leave education. Table 3 shows the top three fields that students wanted to work in. However, 118 students were still undecided on their future career path. ICT was ranked $9^{\text {th }}$ in the list with only 5 students choosing this career path and out of the five, only one student was female.

\begin{tabular}{|c|c|c|c|c|c|c|}
\hline Career & European & $\begin{array}{l}\text { New } \\
\text { Zealand }\end{array}$ & Maori & Pacific & Asian & Others \\
\hline \multicolumn{7}{|l|}{ Medical } \\
\hline Female & 21 & 9 & 3 & 2 & 3 & 1 \\
\hline \multicolumn{7}{|c|}{ Creativity } \\
\hline \multirow[t]{2}{*}{ Female Male } & 3 & 5 & 5 & 1 & O & $\mathrm{O}$ \\
\hline & 5 & 3 & 0 & 3 & o & o \\
\hline \multicolumn{7}{|c|}{ Science } \\
\hline \multirow[t]{2}{*}{ Female Male } & 2 & 12 & $\mathrm{O}$ & $\mathrm{O}$ & $\mathrm{O}$ & $\mathrm{O}$ \\
\hline & 4 & $\mathrm{O}$ & $\mathrm{O}$ & $\mathrm{O}$ & $\mathrm{O}$ & $\mathrm{O}$ \\
\hline \multicolumn{7}{|c|}{ ICT } \\
\hline \multirow[t]{2}{*}{ Female Male } & 1 & $\mathrm{O}$ & $\mathrm{O}$ & O & $\mathrm{O}$ & 0 \\
\hline & 2 & 2 & $\mathrm{O}$ & $\mathrm{O}$ & $\mathrm{O}$ & $\mathrm{O}$ \\
\hline
\end{tabular}

Table 3. Future career path

\subsection{Section B - Cultural factors}

The next section of the questionnaire was around cultural factors. These questions engaged participants from the influence of background, culture and family and elicited responses about where the participants 
got information about careers and how it would impact their own perceptions of ICT. Each set of answers given by participants were combined, totally agree with agree and the same for totally disagree and disagree. The Chi Squared test (CS) and the $p$ value results are provided in table 4 .

\begin{tabular}{lllllllllll}
\hline Girls & \multicolumn{10}{c}{ Boys } \\
\hline Item & Agree & Neutral & Disagree & CS & $p$ & Agree & Neutral & Disagree & CS & $p$ \\
\hline B4 & $81(49 \%)$ & $17(10 \%)$ & $69(41 \%)$ & 41.6 & $<0.05$ & $73(61 \%)$ & $14(12 \%)$ & $32(27 \%)$ & 46.1 & $<0.05$ \\
B6 & $67(40 \%)$ & o(0\%) & $100(60 \%)$ & 6.52 & $>0.05$ & $72(61 \%)$ & $0(0 \%)$ & $47(39 \%)$ & 5.25 & $>0.05$ \\
B7 & $36(22 \%)$ & $28(17 \%)$ & $103(62 \%)$ & 60.9 & $<0.05$ & $53(45 \%)$ & $25(21 \%)$ & $41(34 \%)$ & 9.9 & $>0.05$ \\
B9 & $46(28 \%)$ & $25(15 \%)$ & $96(57 \%)$ & 47.8 & $<0.05$ & $55(46 \%)$ & $26(22 \%)$ & $38(32 \%)$ & 10.7 & $<0.05$ \\
\hline
\end{tabular}

Table 4. Questions on cultural factors

Question B4 hypothesised that parents or guardians would be influential over their child's future career. It was found that boys agreed with the hypothesis and girls also agreed that family members could be influential over their future career but to a slightly lesser extent. It appears that boys are more inclined to seek guidance from family members when thinking about their future career than females. Question B6 hypothesised that ICT was just programming. CS test found that there was no significant difference between the boys and girls. It appears that both girls and boys still agree that ICT is all about programming and nothing else. Question B7 hypothesised that family would encourage their child to take ICT at high school. Girls significantly disagreed that family encouraged them to consider ICT. Boys disagreed but was not a significant finding. It appears the parents or guardians of neither the girls nor boys to a great extent encouraged them to take ICT at high school. Question B9 hypothesised that the participant families' views of ICT will affect young people choosing ICT as a career. Girls significantly disagreed with the hypothesis regarding family views of ICT compared to the boys who disagreed. It appears that girls are more inclined than boys to disagree with certain advice from family when it comes to a future career choice.

\subsection{Section C - Social factors}

The next set of questions asked the participants about their perceptions of stereotyping and role models that would influence them about ICT. These questions tried to understand if stereotypes play a role in Year 11 participants' perceptions of whether role models can influence them towards a certain career path and also do peers have any impact on their decision making.

\begin{tabular}{lllllllllll}
\hline \multicolumn{1}{l}{ Girls } & \multicolumn{10}{c}{ Boys } \\
\hline Item & Agree & Neutral & Disagree & CS & $p$ & Agree & Neutral & Disagree & CS & $p$ \\
\hline C1 & $60(36 \%)$ & $74(44 \%)$ & $33(20 \%)$ & 15.6 & $<0.05$ & $37(31 \%)$ & $51(43 \%)$ & $31(26 \%)$ & 5.3 & $>0.05$ \\
C4 & $117(70 \%)$ & $25(15 \%)$ & $25(15 \%)$ & 104.4 & $<0.05$ & $48(40 \%)$ & $50(42 \%)$ & $21(18 \%)$ & 13.2 & $<0.05$ \\
$C 8$ & $91(54 \%)$ & $65(39 \%)$ & $11(7 \%)$ & 59.8 & $<0.05$ & $59(49 \%)$ & $45(38 \%)$ & $15(13 \%)$ & 25.5 & $<0.05$ \\
$C 9$ & $102(61 \%)$ & $38(22 \%)$ & $27(17 \%)$ & 58.9 & $<0.05$ & $60(50 \%)$ & $38(32 \%)$ & $21(18 \%)$ & 19.2 & $<0.05$ \\
\hline
\end{tabular}

Table 5. Questions on Social factors

Question C1 hypothesised that there is still a problem with stereotyping within the ICT community. It was found that girls agreed with the hypothesis and boys found that they believe there is still stereotyping in the ICT community but was not significant. Question $\mathrm{C}_{4}$ asked whether film and TV show females and males in a stereotypical view, when it comes to ICT. Girls significantly agreed with the stereotypical view and boys agreed but to a much lesser extent. It appears that girls view the ICT industry under the influence of film and TV, giving the perception that key roles show actors as 'geeky' or 'nerdy'. Question C8 asked, should there be younger role models in ICT? Girls significantly agreed there should be younger role models and boys slightly lesser extent also agreed. It appears that girls would like to see younger role models in the ICT sector, including high school. Question C9 hypothesised about role models and do they play a big part in you choosing your future career. It was found that girls like to look up to a role model that they can relate to. Boys also see role models playing a part in them choosing a future career path. It appears that girls more than boys use role models as part of choosing 
their future career. Students still see role models as a major influence on choosing a careerpath.

\subsection{Section D - Structural Factors}

The next set of questions that the participants were exposed to addressed external factors that influence the participant from high school and industry. This section also explored the perception of ICT and the type of work they could be doing in a future career.

\begin{tabular}{llllllllllll}
\hline \multicolumn{1}{l}{ Girls } & \multicolumn{10}{c}{ Boys } \\
\hline Item & Agree & Neutral & Disagree & CS & $p$ & Agree & Neutral & Disagree & CS & $p$ \\
\hline D1 & $106(63 \%)$ & $31(18 \%)$ & $30(19 \%)$ & 68.3 & $<0.05$ & $34(29 \%)$ & $53(44 \%)$ & $32(27 \%)$ & 6.8 & $>0.05$ \\
D2 & $131(78 \%)$ & $36(22 \%)$ & o(0\%) & 54.0 & $<0.05$ & $83(70 \%)$ & $36(30 \%)$ & $0(0 \%)$ & 18.6 & $<0.05$ \\
D1O(a) & $130(78 \%)$ & $37(22 \%)$ & $0(0 \%)$ & 51.8 & $<0.05$ & $91(76 \%)$ & $28(24 \%)$ & $0(0 \%)$ & 33.4 & $<0.05$ \\
D1O(b) & $73(44 \%)$ & $70(42 \%)$ & $24(16 \%)$ & 19.3 & $<0.05$ & $42(35 \%)$ & $55(46 \%)$ & $22(19 \%)$ & 7.5 & $<0.05$ \\
\hline
\end{tabular}

Table 6. Questions on Structural factors

Question D1 asked if participants wanted ICT to be compulsory in high school. Girls significantly disagreed that ICT should be compulsory. Boys were slightly lower than what was expected and was found not to be significant. It does appear that girls are very averse to having ICT made compulsory at high school. Question D2 asked about the work they do at high school in ICT and if they believe it reflects the type of work you would do in an ICT job. It was found that girls agreed that work in high school related to ICT reflects their perceptions of the industry, boys also agreed to a slightly lesser extent. It appears that girls slightly more than boys think the work they do in high school in the ICT lessons would be the same type of work that they would carry out if they were in an ICT job. Question D1o investigated some of the most common types of perceptions the students have about ICT. The perceptions were as follows: ICT is more for men than women, Studying ICT will lock you into a specific job, ICT work is fun, ICT work is repetitive, ICT means working on your own and ICT is not necessary for my future career. It was found that there was a small significant difference between girls and boys regarding the question about future career in ICT, girls and boys. The next significant difference found was for the perception about ICT work is fun. Girls disagreed with the statement but the boys agreed it was fun, but there was no significant difference found for the boys. It appears that there are still a lot of stereotypical views and perceptions about the IT work not being fun and ICT not being necessary for their future career.

\section{5 \#Social IT factors}

The final set of questions investigated factors affecting the participants' perceptions of what the future holds for ICT. \#Social IT is about pursuing passions, creating amazing things using existing, evolving and future technologies and adjusting quickly to an ever-changing technical world.

\begin{tabular}{llllllllllll}
\multicolumn{1}{l}{ Girls } & \multicolumn{10}{c}{ Boys } \\
Item & Agree & Neutral & Disagree & CS & $p$ & Agree & Neutral & Disagree & CS & $p$ & \\
\hline E4 & $97(58 \%)$ & $70(42 \%)$ & o (0\%) & 4.4 & $>0.05$ & $76(64 \%)$ & $43(36 \%)$ & 0 (0\%) & 9.2 & $<0.05$ \\
E5 & $74(44 \%)$ & $76(45 \%)$ & $17(11 \%)$ & $40.3<0.05$ & $49(41 \%)$ & $58(49 \%)$ & $12(10 \%)$ & 29.6 & $<0.05$ \\
\hline
\end{tabular}

Table 7. Questions on \#SocialIT factors

Question E4 hypothesised that you have to be technically minded to be able to work in the ICT industry. It was found that boys agreed regarding the hypothesis. Girls agreed that you have to be technically minded to be able to work in the ICT industry, however this was not a significant finding. It appears that stereotypical views that a person working in the ICT sector must be technical to continue to thrive among students, especially boys. Question E5 asked about the participants' perceptions regarding whether creativity and imagination are required if they wanted to go into the ICT industry. It was found girls significantly agreed that these qualities were good to have and boys agreed but to a slightly less extent. It appears both girls and boys, but slightly more girls recognised that such qualities as 
imagination and creativity are good skills to have to help further participants' careers not only in the ICT sector but in any sector.

\section{Discussion}

From the questions asked of the year 11 students, it appears that girls more than boys at year 11 seem to have more focus in their future career path. They seem to know where they want to go, and influential factors such as family do not appear to change their minds. Boys, it appears, look towards parents and guardians for insight and guidance towards their future career path. These results differ from Dimitriadi (2013) who suggested that cultural influences are strong especially when related to parental roles.

With regards to stereotyping, it was reported that stereotypes are still alive in Year 11 students' perceptions. These results have not really changed in the past 20 years as described by Fisher et al. (2015), who noted "many girls considered IT subjects to be too theoretical, rigidly structured and boring" (p. 2). It does not seem to be a cultural thing but a social theme; however, these results differ from Grant et al. (2007) who talked about geek and loner as not being indicative of the stereotypes that students thought of when referring to people in the industry. Stereotypes are having an effect on Year 11 girls' perceptions of ICT through education and also the industry. From the data, it can be established that the link between stereotypical views and TV/Film is propagated through to what people watch and girls are picking up on these subtle nuances about stereotypes a lot more than the boys.

Role models contribute to Year 11 girls' decisions about their future career; however, when the ICT industry is lacking in high profile younger role models, it is not surprising that fewer girls want to pursue ICT as a career. This supports findings by Dimitriadi (2013) related to culture, especially for nonwesternised cultures and looking up to family members as role models; however, Perciva (2014) found girls have turned off STEM subjects when pretty young females were roles model. This could indicate a difference in western culture compared to other cultures.

When it comes to ICT being compulsory at high school, girls appear to believe that ICT should not be compulsory, but boys were unsure if ICT should be part of a compulsory curriculum. These results back up the evidence from Dimitriadi (2013) who concluded that the classroom experience becomes a major factor for girls to choose other avenues when it comes to their future career path, as the experience in ICT, technology or computing compounds their perceptions about the subject as being boring, believing there should be more female technical teachers to make the subject more fun and not as repetitive.

It does appear that some perceptions are changing regarding the work done in ICT as both the girls and boys recognised that ICT is no longer working on your own but in collaboration with others. These results differ greatly from those of Clayton et al. (2009) who talked about working alone. Girls more than boys think that you must be technical to work in the industry. This supports findings from previous literature from (Gorden 2011; Marghitu et al. 2014; Pau 2009). Both girls and boys, but slightly more girls, believe that creativity and imagination are good assets to have if you are going into the ICT industry. The principal contribution from this paper is the adaptation of a theoretical framework from Bernhardt (2014) to a changing ICT environment in which social media play an increased role. Application of the framework in this environment produced a set of results that quantified differences perceived by practitioners and reported anecdotally. The modified framework also provides practitioners with indicators of actions that might be taken to encourage interest by girls in ICT.

\section{Moving forward}

Based on this research the authors suggest a number of possible solutions and implications. Firstly, embedding ICT within the curriculum from primary school through to high school would allow students to interact with computing at an early age, however it must conform to the new generation's idea of computing and not the stereotypical ideological understanding of just using office and writing code. It also should allow students to be creative in their approach to ICT, allowing collaboration across subject content.

High schools also need to be more agile when it comes to teaching ICT. The need to change is a must for the future of the industry and making it gender neutral. New Zealand education needs to embrace change more rapidly to allow this new disruptive environment to flourish. Being able to offer ICT, technology or computing to students which is embedded into all subject and allows collaboration across subjects is a definite must for all generation $\mathrm{Z}$ students. It is also necessary to educate students that ICT has more to offer than just programming; through working with employers and a diverse set of role models would open their eyes to the possibility that working in the ICT industry is not one industry but every industry in today's society. 
Employers also must show students that there is a diverse culture and mind-set based on today's generation within their organisations to entice girls of all ethnicities that their workplace is a safe and welcoming place to work. If the industry cannot start to show a diverse gender balance and genderneutral workforce, then it will have an impact on students' perceptions which 'fans the flames' of those stereotypes of the industry. If different ethnicities such as Pacific and Māori girls cannot see likeminded people within the industry, then it starts to promote those doubts about are you the right colour and gender fit for ICT. Many larger companies in New Zealand need to start to think about moving into a 21st century disruptive business model rather than the old 2oth century industrial model of doing business.

This research has a limited number of participants across six different high schools in Wellington, having a greater number of participants would allow the research to start to explain some of the questions that did not have enough representation from different cultures. Being able to re-run the questionnaire with more input from both Pacific and Māori would expand the results and give clearer conclusions rather than more of a generalisation. It would be recommended that this questionnaire was also delivered across main centres, such as Hamilton, Christchurch and Dunedin to acquire a better cross section of the country. It would also be recommended that the questionnaire was delivered to rural areas, to see what impact this had on high schools teaching ICT and family culture.

Further research is underway with an interview phase with students that took part in the questionnaire to address some of those underlying perceptions in greater detail to fully understand why those students perceived ICT in that way.

\section{Conclusion}

Based on the results presented above, it can be concluded from the cultural factors that boys seek approval more than girls when it comes to family, as girls seem to be more focused regarding their future direction. As for the social factors, nothing has changed in the last 20 years when it comes to stereotypes in ICT. Both girls and boys still perceive this as a big stumbling block for them and are put off by these stereotypical perceptions and become reluctant to follow a career in ICT. Girls slightly more than boys look to role models who share similar characteristics. However, role models that go against the students' own self-image, can negatively influence their career choices.

When it came to the structural factors and ICT being compulsory, the girls were adamant and disagreed completely with this statement; however, many of the students commented that embedding ICT within all subjects would be a better solution. From the \#SocialIT factor, the ICT sector in the next 10 years will be a very exciting place to work and girls seemed to understand more than the boys that the opportunities that lie ahead could be very rewarding.

However, when you add up all the results regarding the likelihood of females choosing ICT as a career path the numbers of students wanting to go into the industry or study ICT fall very short. Until government, education and industry start collaborating and being proactive in change, the majority of these students who will be heading off in the next couple of years to university or to start their future careers will not contemplate seeking employment in the ICT industry.

\section{References}

"2012 Australian ICT Statistical Compendium. 2012." Australian Computer Society, Sydney, NSW, p 80.

"2013/2017 New Zealand Census." 2017. Retrieved July, 2018, from http://nzdotstat.stats.govt.nz/wbos/Index.aspx

Adya, M., and Kaiser, K. M. 2005. "Early determinants of women in the IT workforce: a model of girls' career choices," Information Technology \& People (18:3), pp 230-259.

Almond, S. 2013. "My kids are obsessed with technology, and it's all my fault." The New York Times Retrieved June, 2018, from https://www.nytimes.com/2013/06/23/magazine/my-kids-areobsessed-with-technology-and-its-all-my-fault.html

Baruch, R. 2014. "Women and Information Technology: How Do Female Students of Education Perceive Information Technology, and What is Their Approach toward It?," Journal of International Women's Studies (15:1), pp 190-214.

Bernhardt, S. 2014. Women in IT in the New Social Era: A Critical Evidence-Based Review of Gender Inequality and the Potential for Change. Hershey, PA, USA: IGI Global.

Birrell, B. 2015. "Too few or perhaps too many STEM graduates," Australian Universities' Review, The 
(57:2), pp. 71-78.

Broadley, K. 2015. "Entrenched gendered pathways in science, technology, engineering and mathematics: Engaging girls through collaborative career development," Australian Journal of Career Development (24:1), pp 27-38.

Cappelli, P. H. 2015. "Skill Gaps, Skill Shortages, and Skill Mismatches: Evidence and Arguments for the United States," ILR Review (68:2), pp 251-290.

Clayton, K. 2006. "Attitudes Towards ICT in Australian High Schools," Encyclopedia of Gender and Information Technology:2002), pp 3384-3390.

Clayton, K., Beekhuyzen, J., and Nielsen, S. 2012. "Now I know what ICT can do for me!," Information Systems Journal (22:5), pp 375-390.

Clayton, K., Hellens, L. V., and Nielsen, S. H. 2009. "Gender Stereotypes Prevail in ICT ; a Research Review," Proceedings of the special interest group on management information system's 47th annual conference on Computer personnel research, ACM, Limerick, Ireland: ACM New York, NY, USA pp 153-158.

Craig, A. 2014. "Australian interventions for women in computing: Are we evaluating?," Australasian Journal of Information Systems (18:2), pp 91-110.

Dimitriadi, A. 2013. "Young women in science and technology: the importance of choice," Journal of Innovation and Entrepreneurship (2:1), pp 5-5.

Fisher, J., Lang, C., Craig, A., and Forgasz, H. 2015. "If girls aren't interested in computers can we change their minds?," ECIS 2015: Proceedings of the 23rd Information Systems European Conference: AIS Electronic Library, pp 1-14.

Fortt, J. 2013. "More women in technology job? If only it were true." Retrieved July, 2018, from https://www.cnbc.com/2013/11/21/more-women-in-technology-jobs-if-only-it-weretrue.html

Gorden, C. 2011. "Women in Tech: Why is there no female Steve Jobs." from http://jobs.aol.com/articles/2011/10/31/women-in-tech-why-is-there-no-female-stevejobs/

Grant, D. M., Knight, L. V., and Steinbach, T. A. 2007. "Young Women 's Misinformation Concerning IT Careers : Exchanging One Negative Image for Another," Informing Science Journal (10), pp 91-106.

Jones, C., and Ramanau, R. 2009. "Collaboration and the Net generation: The changing characteristics of first year university students," Proceedings of the 9th international conference on Computer supported collaborative learning-Volume 1: International Society of the Learning Sciences, pp 237-241.

Jones, D., Albion, P. R., and Heffernan, A. 2016. "Mapping the digital practices of teacher educators: Implications for teacher education in changing digital landscapes," Society for Information Technology \& Teacher Education International Conference, pp 4871-4879.

Koulopoulos, T. M., and Keldsen, D. 2014. The Gen $Z$ effect: the six forces shaping the future of business. Brookline, MA: Bibliomotion, Inc.

Marghitu, D., Hur, J. W., Rawajfih, Y., Hall, J., and Stephens, C. 2014. "Promoting Computer Science among Girls: An Auburn University Pilot Program," in: Society for Information Technology \& Teacher Education International Conference 2014, M. Searson and M.N. Ochoa (eds.). Jacksonville, Florida, United States: Association for the Advancement of Computing in Education (AACE), pp 112-119.

Outlay, C., Platt, A., and Conroy, K. 2017. "Getting IT Together: A Longitudinal Look at Linking Girls' Interest in IT Careers to Lessons Taught in Middle School Camps," ACM Transactions on Computing Education (TOCE) (17:4), pp 1-17.

Pau, R. 2009. "Experiental factors which influence how female students preceive computing and computing careers at different stages in their education." Thesis (PhD): University of Southampton, UK, p 274.

Perciva, J. 2014. "No George Osborne! Girls will not follow glamorous role models into science, Higher Education Network " The Guardian, from http://www.theguardian.com/higher-educationnetwork/blog/2014/may/28/no-george-osborne-girls-will-not-follow-pretty-role-modelsinto-science

Piyasiri, T. A., Padmashanthi, Y. G., and Manathunga, Y. S. 2014. "Study on career guidance in general education in Sri Lanka." Retrieved July, 2018, from http://nec.gov.lk/study-on-careerguidance-in-general-education-in-sri-lanka-research-series-2014/

Ryan, H. 2015. "ICT Qualification 'Essential' for All School Leavers." Retrieved August, 2018, from http://www.jetmag.co.nz/ict-qualification-essential-for-all-school-leavers/ 
Australasian Conference on Information Systems

2018, Sydney, Australia

"Seek ICT Jobs." 2018. Retrieved 17th April, 2018, from https://www.seek.co.nz/jobs-in-informationcommunication-technology

Wiedmer, T. 2015. "Generations Do Differ: Best Practices in Leading Traditionalists, Boomers, and Generations X, Y, and Z," Delta Kappa Gamma Bulletin (82:1), pp 51-58.

Copyright: (C) 2018 Morton, Redmond, Albion. This is an open-access article distributed under the terms of the Creative Commons Attribution-NonCommercial 3.0 Australia License, which permits non-commercial use, distribution, and reproduction in any medium, provided the original author and $\mathrm{ACIS}$ are credited. 